\title{
COMPARATIVE ANALYSIS OF MYRINGOPLASTY VS TYMPANOMASTOIDECTOMY (TYPE 1) IN TUBOTYMPANIC TYPE OF CHRONIC OTITIS MEDIA
}

\author{
Bibhuti Das ${ }^{1}$ Debajit Das ${ }^{2}$
}

${ }_{1}^{1}$ Registrar, Department of ENT, FAAMCH, Barpeta, Assam.

2 Professor and HOD, Department of ENT, AMCH, Dibrugarh, Assam.

\begin{abstract}
BACKGROUND

Chronic Suppurative Otitis Media (CSOM) is one of the most common causes of ear infection in developing countries, particularly in Southeast Asian countries. Even with advent of newer antibiotics and better health facilities, CSOM is still a widely encountered clinical entity in our country. Prevalence surveys show that the global burden of illness from CSOM involves 65 - 330 million individuals with draining ears. Over $90 \%$ of the burden is borne by countries in the Southeast Asia and Western Pacific regions, Africa and several ethnic minorities in the Pacific Rim affecting both the sexes and all age groups. ${ }^{1}$ The term "Tubotympanic disease" is sometimes used to describe COM with a central perforation. The two principal aims of management of tubotympanic, chronic otitis media are the eradication of infection and improvement of hearing by the closure of the tympanic membrane perforation which can be achieved either conservatively or by surgery. Some surgeons advice only repair of central perforation of tympanic membrane using graft, i.e. myringoplasty. Cortical mastoidectomy can be combined with type 1 tympanoplasty to achieve a dry, safe and trouble free ear. However, the role of mastoidectomy in tubotympanic chronic otitis media is still controversial.

This study aims to analyse the outcomes of myringoplasty vs cortical mastoidectomy with type-1 tympanoplasty in patients of tubotympanic type CSOM.
\end{abstract}

\section{MATERIALS AND METHODS}

This hospital-based prospective study was done in the Dept. of Otorhinolaryngology, Assam Medical College and Hospital, Dibrugarh from 1st January 2015 to 31st December 2015 in diagnosed cases of tubotympanic variant of CSOM. Sixty patients were included in the study, which were randomly divided into two groups each comprising thirty patients. Group A patients underwent Myringoplasty, while Group B patients underwent Type 1 Tympanomastoidectomy. The surgical outcomes were assessed in terms of hearing gain, graft uptake and dryness of ear.

\section{RESULTS}

Sixty cases of tubotympanic type of CSOM were reviewed in the study with male-to-female ratio of 1:1.61.30 patients (Group A) underwent myringoplasty, while 30 (Group B) underwent Type 1 Tympanomastoidectomy. Gain in hearing was $9.90 \pm 1.81 \mathrm{db}$ and $10.666 \pm 2.07 \mathrm{db}$ in Group A and Group B respectively, which was statistically similar $(\mathrm{p}=0.1305)$. Successful graft uptake was seen in $83.33 \%$ and $80 \%$ of cases in Group A and Group B respectively, which was also statistically similar $(p=1.00)$. Dry ear was achieved in $86.67 \%$ and $93.37 \%$ cases in Group A and Group B respectively, which was statistically insignificant ( $p=0.6707)$.

\section{CONCLUSION}

Myringoplasty and tympanomastoidectomy has been identified as an effective method of surgical treatment of tubotympanic variant of CSOM. Our study concluded that surgical outcomes of myringoplasty and type 1 tympanomastoidectomy in tubotympanic type of chronic otitis media in terms of gain in hearing, graft uptake and dryness of ear were statistically similar. Therefore, while considering the addition of a mastoidectomy to a myringoplasty, the performing surgeon should consider the potential risks and costs to the patient.

\section{KEYWORDS}

Chronic Otitis Media, Tubotympanic Type, Myringoplasty, Tympanomastoidectomy Type 1.

HOW TO CITE THIS ARTICLE: Das B, Das D. Comparative analysis of myringoplasty vs tympanomastoidectomy (type 1) in tubotympanic type of chronic otitis media. J. Evolution Med. Dent. Sci. 2017;6(19):1483-1488, DOI: 10.14260/Jemds/2017/325

\section{BACKGROUND}

Chronic Suppurative Otitis Media (CSOM) is one of the most common causes of ear infection in developing countries, particularly in Southeast Asian countries.

Financial or Other, Competing Interest: None.

Submission 28-01-2017, Peer Review 21-02-2017,

Acceptance 27-02-2017, Published 06-03-2017.

Corresponding Author:

Dr. Bibhuti Das,

C/o. Amiya Kumar Das,

House No. 143, Saurav Nagar

Beltola, Guwahati-781028,

Dist. Kamrup Metro, Assam.

E-mail: drbibhutidas9@gmail.com

DOI: $10.14260 /$ jemds $/ 2017 / 325$
Prevalence surveys which vary widely in disease definition, sampling methods and methodologic quality show that the global burden of illness from CSOM involves 65 - 330 million individuals with draining ears, $60 \%$ of whom (39200 million) suffer from significant hearing impairment. CSOM accounts for 28,000 deaths and a disease burden of over 2 million DALYs. Over $90 \%$ of the burden is borne by countries in the Southeast Asia and Western Pacific regions, Africa and several ethnic minorities in the Pacific Rim affecting both the sexes and all age groups. ${ }^{1}$ In the developing countries still, poverty, ignorance, dearth of specialists and limited access to medical care amongst others conspire to worsen the course and complications (sometimes lifethreatening) of CSOM.2,3 The recent study shows prevalence 
of chronic otitis media in rural Indian population is 46 per 1000 and in urban population is 16 per $1000 .^{1}$

A unifying definition of the term "chronic otitis media" is any structural change in the middle ear system associated with a permanent defect in the Tympanic Membrane (TM). The condition is considered "chronic," if the TM defect is present for a period greater than 3 months. ${ }^{4}$

Chronic otitis media results from long-term Eustachian tube dysfunction with a poorly aerated middle-ear space, multiple bouts of acute otitis media, persistent middle-ear infection, allergy or other chronic inflammatory stimulus. ${ }^{5}$

The term "Tubotympanic disease" is sometimes used to describe COM with a central perforation, which can be achieved either conservatively or by surgical approach. Conservative measures aim to achieve dry ear and limit the infection or inflammation by aural toilet and antimicrobial therapy.

\section{The Priorities of Surgery in Tubotympanic CSOM are-}

(1) Eradication of disease,

(2) Prevention of disease recurrence, and

(3) Preservation or restoration of hearing. 6

The surgical treatment of CSOM is still controversial. Some surgeons advice only repair of central perforation of tympanic membrane using graft, i.e. myringoplasty.

Cortical mastoidectomy can be combined with type 1 tympanoplasty, which is however still controversial. This study aims to analyse the outcomes of myringoplasty vs cortical mastoidectomy with type 1 tympanoplasty in patients of tubotympanic type of COM.

\section{MATERIALS AND METHODS}

This hospital-based prospective study was conducted in the Department of ENT - Head and Neck Surgery, Assam Medical College and Hospital, Dibrugarh, Assam for a period of 1 year from $1^{\text {st }}$ January 2015 to $31^{\text {st }}$ December 2015.

\section{Aims and Objectives}

To evaluate the surgical outcomes of Myringoplasty in comparison to Tympanomastoidectomy (Type 1) in Tubotympanic type of Chronic Otitis Media (COM).

\section{Selection of Cases}

All the cases of tubotympanic type of COM not responding to conservative management attending the Dept. of Otorhinolaryngology, Assam Medical College and Hospital Dibrugarh fulfilling the inclusion and exclusion criteria were included in this study.

\section{Inclusion Criteria}

All the patients diagnosed as tubotympanic type of chronic otitis media with history of discharging ear with central type of tympanic membrane perforation and conductive type of hearing loss with disease free normal middle-ear cavity and mastoid with patent Eustachian tube and patent auditus were included in the study irrespective of age, sex, religion, caste, literacy, geographic location, socio-economic profile and duration of illness after dry ear was achieved conservatively for minimum 4 weeks.

\section{Exclusion Criteria}

1. All cases of acute suppurative otitis media and serous otitis media.

2. CSOM with cholesteatoma, retraction pockets, granulation tissue, marginal and total perforations, polyp in the ear, oedematous and unhealthy middle ear mucosa and ossicular pathology, sensorineural or mixed hearing loss with complications.

3. Traumatic perforation of tympanic membrane.

4. Tubercular otitis media.

5. Patients with past history of ear surgery, i.e. mastoidectomy or myringoplasty, etc.

6. Patients with concomitant illness like any infections of nose, paranasal sinus, nasopharynx or throat, otitis externa, uncontrolled diabetes and hypertension, psychiatric ailments, neurological disorder and immunocompromised status.

\section{Methodology}

- All the patients were subjected to detail history, complete general, systemic and ENT examination after taking proper informed and written consent.

- ENT examination included otoscopy, tuning fork tests, Eustachian tube patency test including inflationdeflation test, impedance audiometry. EUM (Examination Under Microscope), audiological investigation in the form of PTA (Pure Tone Audiometry) and impedance.

- Radiological investigations included $\mathrm{x}$-ray mastoid (Law's lateral oblique view) and HRCT scan of temporal bone both axial and coronal cuts for detailed anatomical evaluation including aditus patency.

- $\quad$ All the cases were initially managed conservatively by aural toileting, antibiotics, antihistaminics and decongestants in order to achieve dry ear for minimum duration of 4 weeks.

- All the cases were prepared for surgery by performing required investigations under general anaesthesia and local anaesthesia according to patient's wish. However general anaesthesia was used in children and excessively apprehensive patients.

- After getting anaesthesia clearance, the cases were randomly divided into two groups.

- Group A - patients who underwent Myringoplasty.

- Group B - patients who underwent Tympanomastoidectomy (Type 1).

\section{Postoperative Care}

Antibiotic prophylaxis was given to all patients started from the day prior to surgery and continued till $3^{\text {rd }} / 4^{\text {th }}$ postoperative day. External mastoid dressing was removed next day after surgery. Patients were discharged on $3^{\text {rd }} / 4^{\text {th }}$ post-operative day with advice to take oral antibiotics, antihistaminics, nasal decongestants and analgesics if required. Patients were asked to attend OT for stitch removal and ear pack removal on $10^{\text {th }}$ postoperative day.

Water precautions were maintained for six weeks and patients were advised to abstain from forceful nose blowing, exposure to cold and swimming. 


\section{Follow-up}

For every case, postoperative followup was done on

- $1^{\text {st }}$ review $-10^{\text {th }}$ day.

- $\quad 2^{\text {nd }}$ review - $3^{\text {rd }}$ week.

- $\quad 3^{\text {rd }}$ review $-12^{\text {th }}$ week.

Surgical success was measured in terms of successful graft uptake, ability to achieve dry ear and improvement in hearing.

During each followup, every patient underwent otoscopy and EUM to assess the graft uptake/graft rejection or reperforation, presence or absence of any ear discharge (dry ear achieved or not). During the $3^{\text {rd }}$ followup, audiological assessment was done in the form of PTA (Pure Tone Audiometry) and the change in the speech frequencies of 500, 1000 and $2000 \mathrm{~Hz}$ was noted. The findings were recorded and analysed to evaluate postoperative hearing improvement by calculating preoperative and postoperative Air-Bone Gap (ABG) and post-operative hearing gain in decibel.

Graft status, dryness of ear and postoperative hearing outcome of each patient in Group A and Group B were evaluated and compared.

\section{Statistical Analysis}

Statistical analysis was done in terms of percentage (\%) and Mean \pm Standard Deviation (S.D.). Statistical significance was calculated by using student's T-Test and Fisher's Exact Test wherever applicable.

\section{RESULTS AND OBSERVATION}

A comparative analysis of surgical outcome of 60 patients of tubotympanic type of CSOM (Group A comprising 30 patients of Myringoplasty and Group B comprising of 30 patients of Tympanomastoidectomy Type 1). Following are the results and observations.

\section{Age and Sex Incidence}

In our study, most of the cases were in the age group $31-40$ years (30\% in Group A and $26.67 \%$ in Group B) followed by the age group 21 - 30 years $(26.67 \%$ in Group A and $23.33 \%$ in Group B); 11 - 20 years' and 41 - 50 years' age group consisted of $16.67 \%$ patients each; $13.33 \%$ of total cases were older than 51 years of age $(16.67 \%$ in Group A and $10.00 \%$ in Group B).

Out of 60 cases 23 (38.33\%) were male, while 37 $(61.67 \%)$ were female. Male-to-female ratio was 1:1.61. Out of 23 males 12 cases underwent myringoplasty, while 11 underwent tympanomastoidectomy type 1 . Similarly, out of 37 females 18 and 19 patients were included in Group A and Group B respectively.

\begin{tabular}{|c|c|c|c|c|c|}
\hline \multirow{2}{*}{$\begin{array}{c}\text { Age } \\
\text { (in Years) }\end{array}$} & \multicolumn{2}{|c|}{$\begin{array}{c}\text { Group A } \\
\text { (n= 30) }\end{array}$} & \multicolumn{2}{c|}{$\begin{array}{c}\text { Group B } \\
\text { (n= 30) }\end{array}$} & \multirow{2}{*}{$\begin{array}{c}\text { Total } \\
(\mathbf{n}=\mathbf{6 0})\end{array}$} \\
\cline { 2 - 5 } & No. & $\%$ & No. & $\mathbf{\%}$ & \\
\hline$<10$ & - & - & - & - & \\
\hline $11-20$ & 4 & 13.33 & 6 & 20 & $10(16.67 \%)$ \\
\hline $21-30$ & 8 & 26.67 & 7 & 23.33 & $15(25 \%)$ \\
\hline $31-40$ & 9 & 30 & 8 & 26.67 & $17(28.33 \%)$ \\
\hline $41-50$ & 4 & 13.33 & 6 & 20 & $10(16.67 \%)$ \\
\hline$>51$ & 5 & 16.67 & 3 & 10 & $8(13.33 \%)$ \\
\hline Mean \pm S.D & $35.16 \pm 12.75$ & $33.6 \pm 12.93$ & \\
\hline \multicolumn{6}{|c|}{ Table 1. Age Distribution } \\
\hline
\end{tabular}

\begin{tabular}{|c|c|c|c|c|c|}
\hline \multirow{2}{*}{ Gender } & \multicolumn{2}{|c|}{$\begin{array}{c}\text { Group A } \\
(\mathbf{n = 3 0 )}\end{array}$} & \multicolumn{2}{c|}{$\begin{array}{c}\text { Group B } \\
(\mathbf{n = 3 0}\end{array}$} & \multirow{2}{*}{$\begin{array}{c}\text { Total } \\
(\mathbf{n = 6 0})\end{array}$} \\
\cline { 2 - 5 } & No. & $\mathbf{\%}$ & No. & $\mathbf{\%}$ & \\
\hline Male & 12 & $40 \%$ & 11 & $36.67 \%$ & $23(38.33 \%)$ \\
\hline Female & 18 & $60 \%$ & 19 & $63.33 \%$ & $37(61.67 \%)$ \\
\hline \multicolumn{6}{|c|}{ Table 2. Sex Distribution } \\
\hline
\end{tabular}

20 patients $(33.33 \%)$ had clinical presentation on right side $(26.67 \%$ in Group A and $40 \%$ in Group B), while 30 patients (50\%) had clinical presentation on left side $(53.33 \%$ in Group A and 46.67\% in Group B); 10 cases (16.67\%) had bilateral clinical presentation (20\% in Group A and $13.33 \%$ in Group B). In these 10 cases, worst ear was operated.

\begin{tabular}{|c|c|c|c|c|c|}
\hline \multirow{2}{*}{$\begin{array}{c}\text { Side } \\
\text { Involved }\end{array}$} & \multicolumn{2}{|c|}{$\begin{array}{c}\text { Group A } \\
\text { (n= 30) }\end{array}$} & \multicolumn{2}{c|}{$\begin{array}{c}\text { Group B } \\
\text { (n= 30) }\end{array}$} & \multirow{2}{*}{$\begin{array}{c}\text { Total } \\
\text { (n= 60) }\end{array}$} \\
\cline { 2 - 6 } & No & $\mathbf{\%}$ & No & $\mathbf{\%}$ & \\
\hline Right & 8 & $26.67 \%$ & 12 & $40 \%$ & $20(33.33 \%)$ \\
\hline Left & 16 & $53.33 \%$ & 14 & $46.67 \%$ & $30(50 \%)$ \\
\hline Bilateral & 6 & $20 \%$ & 4 & $13.33 \%$ & $10(16.67 \%)$ \\
\hline \multicolumn{6}{|c|}{ Table 3. Distribution of Side of Ear involved at } \\
Presentation
\end{tabular}

$30 \%$ cases had otorrhoea for 7 - 12 months followed by 13 patients (21.67\%) for 13 - 24 months; 7 patients i.e. $13.33 \%$ had otorrhoea for each duration of 25 - 36 months, 49 - 60 months and > 61 months; 5 cases (8.33\%) had otorrhoea for less than 6 months.

\begin{tabular}{|c|c|c|c|c|c|}
\hline \multirow{2}{*}{$\begin{array}{l}\text { Duration of } \\
\text { Discharge } \\
\text { (Months) }\end{array}$} & \multicolumn{2}{|c|}{$\begin{array}{c}\text { Group A } \\
(n=30)\end{array}$} & \multicolumn{2}{|c|}{$\begin{array}{l}\text { Group B } \\
(n=30)\end{array}$} & \multirow[t]{2}{*}{$\begin{array}{c}\text { Total } \\
(n=60)\end{array}$} \\
\hline & No. & $\%$ & No. & $\%$ & \\
\hline$<6$ & 2 & 6.67 & 3 & 10 & $5(8.33 \%)$ \\
\hline $7-12$ & 8 & 26.67 & 10 & 33.33 & $18(30 \%)$ \\
\hline $13-24$ & 7 & 23.33 & 6 & 20 & $13(21.67 \%)$ \\
\hline $25-36$ & 4 & 13.33 & 3 & 10 & 7 (11.67\%) \\
\hline $37-48$ & 2 & 6.67 & 1 & 3.33 & $3(5 \%)$ \\
\hline $49-60$ & 4 & 13.33 & 3 & 10 & $7(11.67 \%)$ \\
\hline$>61$ & 3 & 10 & 4 & 13.33 & $7(11.67 \%)$ \\
\hline \multicolumn{6}{|c|}{$\begin{array}{l}\text { Table 4. Duration of Discharge } \\
\text { (In Months) Preoperatively }\end{array}$} \\
\hline
\end{tabular}

24 cases $(40 \%)$ had large central perforation of tympanic membrane (Group A $=36.67 \%$ and Group B $=43.33 \%$ ); 11 cases $(36.67 \%)$ underwent myringoplasty, while 8 cases (26.67\%) underwent type 1 tympanomastoidectomy out of 19 cases $(31.67 \%)$ of subtotal perforation. Total 17 cases (28.33\%) had medium tympanic membrane perforation (Group A = 26.67\% and Group B = 30\%).

\begin{tabular}{|c|c|c|c|c|c|}
\hline \multirow{2}{*}{ Perforation } & \multicolumn{2}{|c|}{$\begin{array}{c}\text { Group A } \\
(\mathbf{n = 3 0}\end{array}$} & $\begin{array}{c}\text { Group B } \\
\text { (n= 30) }\end{array}$ & \multirow{2}{*}{$\begin{array}{c}\text { Total } \\
(\mathbf{n = 6 0})\end{array}$} \\
\cline { 2 - 5 } & No. & $\mathbf{\%}$ & No. & $\%$ & \\
\hline $\begin{array}{c}\text { Small Sized } \\
(<25 \%)\end{array}$ & - & - & - & - & - \\
\hline $\begin{array}{c}\text { Medium } \\
(25-50 \%)\end{array}$ & 8 & 26.67 & 9 & 30 & $\begin{array}{c}17 \\
(28.33 \%)\end{array}$ \\
\hline Large (50-75\%) & 11 & 36.67 & 13 & 43.33 & $24(40 \%)$ \\
\hline $\begin{array}{c}\text { Subtotal } \\
(>75 \%)\end{array}$ & 11 & 36.67 & 8 & 26.67 & $\begin{array}{c}19 \\
(31.67 \%)\end{array}$ \\
\hline Table 5. Distribution of Types of Tympanic Membrane \\
Perforation
\end{tabular}


Sclerotic mastoid was seen in $66.67 \%$ cases (Group A $=$ $63.33 \%$ and Group B $=70 \%$ ). Pneumatisation of mastoid was seen in $21.67 \%$ cases (Group $\mathrm{A}=23.33 \%$ and Group $\mathrm{B}=$ $20 \%$ ). Diploic mastoid was seen in $13.33 \%$ cases in Group A and $10 \%$ cases in Group B respectively.

\begin{tabular}{|c|c|c|c|c|c|}
\hline \multirow{2}{*}{$\begin{array}{c}\text { Type of } \\
\text { Cellularity }\end{array}$} & \multicolumn{2}{|c|}{$\begin{array}{c}\text { Group A } \\
(\mathbf{n = 3 0 )}\end{array}$} & \multicolumn{2}{c|}{$\begin{array}{c}\text { Group B } \\
(\mathbf{n = 3 0}\end{array}$} & \multirow{2}{*}{$\begin{array}{c}\text { Total } \\
(\mathbf{n}=\mathbf{6 0})\end{array}$} \\
\cline { 2 - 5 } & No. & $\mathbf{\%}$ & No. & $\mathbf{\%}$ & \\
\hline Pneumatic & 7 & $23.33 \%$ & 6 & 20 & $13(21.67 \%)$ \\
\hline Sclerotic & 19 & 63.33 & 21 & 70 & $40(66.67 \%)$ \\
\hline Diploic & 4 & 13.33 & 3 & 10 & $7(11.67 \%)$ \\
\hline Table 6. Distribution on the basis of Cellularity of Mastoid \\
as viewed on X-Ray/CT-Scan \\
\hline
\end{tabular}

Preoperative air-bone gap, $\mathrm{ABG}(\mathrm{AC}-\mathrm{BC})$ was in the range of $31-40 \mathrm{db}$ in 17 cases in Group A and 18 cases in Group B respectively; 13 cases in Group A and 11 cases in Group B had $A B G$ in the range of $21-30 \mathrm{db} ; 1$ case had $A B G$ in the range of 41 - $50 \mathrm{db}$ (Group B).
The mean preoperative ABG in Group A and Group B was $31.766 \pm 3.94$ and $32.03 \pm 4.23 \mathrm{db}$ respectively. The $P$ value was 0.8063 (calculated by student's ' $\mathrm{T}$ ' test), which was statistically insignificant.

Postoperative air-bone gap, ABG was in the range of 21 $30 \mathrm{db}$ in 15 cases (50\%) in Group A followed by 14 cases $(46.67 \%)$ in the range of $11-20 \mathrm{db}$ and 1 case $(3.33 \%)$ in the range of $31-40 \mathrm{db}$ respectively. Similarly, in Group B 16 cases (53.33\%) had ABG in the range of $21-30 \mathrm{db}$ followed by 13 cases $(43.33 \%)$ in the range of $11-20 \mathrm{db}$ and 1 case $(3.33 \%)$ in the range of $31-40 \mathrm{db}$ respectively.

Mean postoperative ABG in Group A and Group B were $21.866 \pm 4.98 \mathrm{db}$ and $21.366 \pm 4.16 \mathrm{db}$ respectively. The $\mathrm{p}$ value was 0.6746 , that is statistically insignificant. The gain in hearing at $3^{\text {rd }}$ postoperative review was $9.90 \pm 1.81 \mathrm{db}$ and $10.666 \pm 2.07 \mathrm{db}$ respectively in Group A and Group B. The $p$ value is 0.1305 , which is statistically insignificant. In this audiological assessment, the $p$ value is calculated by Student's T-Test.

\begin{tabular}{|c|c|c|c|}
\hline Audiological Assessment & Group A (In db) & Group B (In db) & P value \\
\hline Mean preoperative AC & $41.13 \pm 4.58$ & $40.166 \pm 4.98$ & $0.4402(\mathrm{NS})$ \\
\hline Mean preoperative BC & $9.366 \pm 2.11$ & $8.066 \pm 2.63$ & \\
\hline Mean preoperative ABG & $31.766 \pm 3.94$ & $32.03 \pm 4.23$ & $0.8063(\mathrm{NS})$ \\
\hline Mean postoperative AC (3rd review) & $31.233 \pm 5.81$ & $29.50 \pm 4.68$ & $0.2091(\mathrm{NS})$ \\
\hline Mean postoperative BC (3rd review) & $9.366 \pm 2.11$ & $8.066 \pm 2.63$ & $0.6746(\mathrm{NS})$ \\
\hline Mean postoperative ABG (3rd review) & $21.866 \pm 4.98$ & $21.366 \pm 4.16$ & $0.1305(\mathrm{NS})$ \\
\hline Gain in hearing (3rd review) & $9.90 \pm 1.81$ & $10.666 \pm 2.07$ & \\
\hline \multicolumn{4}{|l}{ Table 7. Audiological Assessment }
\end{tabular}

All the 30 cases in each Group A and Group B had successful graft uptake in the $1^{\text {st }}$ followup on $10^{\text {th }}$ postoperative day. In Group A, 2 cases had graft failure at $3^{\text {rd }}$ week and subsequently 5 cases had graft rejection at $3^{\text {rd }}$ followup on $12^{\text {th }}$ week. In Group B, 3 cases had graft rejection at $3^{\text {rd }}$ week and 6 cases had graft rejection at $12^{\text {th }}$ week (3rd review). Successful graft uptake postoperatively at $3^{\text {rd }}$ followup (12 ${ }^{\text {th }}$ week) was seen in $83.33 \%$ of cases in Group A and in $80 \%$ cases in Group B respectively.

\begin{tabular}{|c|c|c|c|c|}
\hline \multirow{2}{*}{$\begin{array}{c}\text { Postoperative } \\
\text { Review }\end{array}$} & \multicolumn{2}{|c|}{ Group A (n = 30) } & \multicolumn{2}{c|}{ Group B (n = 30) } \\
\cline { 2 - 5 } & $\begin{array}{c}\text { Successful } \\
\text { Graft Uptake }\end{array}$ & $\begin{array}{c}\text { Graft } \\
\text { Rejection }\end{array}$ & $\begin{array}{c}\text { Successful } \\
\text { Graft } \\
\text { Uptake }\end{array}$ & $\begin{array}{c}\text { Graft } \\
\text { Rejection }\end{array}$ \\
\hline $\begin{array}{c}1^{\text {st }} \text { review } \\
\left(10^{\text {th }} \text { day) }\right.\end{array}$ & 30 & - & 30 & - \\
\hline $\begin{array}{c}2^{\text {nd }} \text { review } \\
\left(3^{\text {rd }} \text { week }\right)\end{array}$ & 28 & 2 & 27 & 3 \\
\hline $\begin{array}{c}3^{\text {rd }} \text { review } \\
\left(12^{\text {th }} \text { week }\right)\end{array}$ & $25(83.33 \%)$ & 5 & $24(80 \%)$ & 6 \\
\hline \multicolumn{4}{|l|}{ Table 8. Followup Assessment of Graft Status } \\
\hline
\end{tabular}

Dry ear was achieved at the end of $12^{\text {th }}$ week in $86.67 \%$ of cases in Group A and $93.33 \%$ cases in Group B respectively. The $p$ value was 0.6707 (calculated by Fisher's exact test), which is statistically insignificant.

\begin{tabular}{|c|c|c|c|}
\hline $\begin{array}{c}\text { Surgical } \\
\text { Outcome }\end{array}$ & Group A & Group B & P value \\
\hline $\begin{array}{c}\text { Successful graft } \\
\text { uptake }\end{array}$ & $25(83.33 \%)$ & $24(80 \%)$ & $1.00(\mathrm{NS})$ \\
\hline Dry ear & $26(86.67 \%)$ & $28(93.33 \%)$ & $0.6707(\mathrm{NS})$ \\
\hline Gain in hearing & $9.90 \pm 1.81 \mathrm{db}$ & $10.666 \pm 2.07 \mathrm{db}$ & $0.1305(\mathrm{NS})$ \\
\hline \multicolumn{4}{|c|}{ Table 9. Statistical Analysis of Surgical Outcome at 3rd } \\
Followup (12 \\
th Week) \\
\hline
\end{tabular}

\section{DISCUSSION}

This comparative study was conducted in 60 cases, chosen after fulfilling the inclusion and exclusion criteria. The chosen patients were randomly divided into two groups. Group A comprising of 30 cases were subjected to myringoplasty, while Group B consisting of 30 patients were subjected to type 1 tympanomastoidectomy. Epidemiological and clinical profile and surgical outcomes were studied during postoperative followup in both the groups and comparative analysis was made by statistical methods.

In this present study, highest incidence of COM was seen in the age group $31-40$ years $(28.33 \%)$ followed by age group 21 - 30 years (25\%); 11 - 20 years' and 41 - 50 years' age group consisted of $16.67 \%$ patients each; $13.33 \%$ of total cases were older than 51 years of age. The mean ages were $35.16 \pm 12.75$ and $33.6 \pm 12.93$ years in Group A and Group B respectively.

Indorewala et al in their study found that the age of the patients ranged from 5 to 76 years with a mean age of $35 \pm$ 15.8 years; the age group 21 - 40 years was the most affected group (36\%).7 Our findings correlate with this particular study.

This study showed that the male-to-female ratio was 1 : 1.61. However, Browning et al found the incidence of CSOM to be $1.9 \%$ in male and $1.2 \%$ in female. ${ }^{8} \mathrm{~A}$ sex ratio of 1.3 to 1 was found by M. A. Yaor et al in their study. ${ }^{9}$ This study found that $33.33 \%$ patients had clinical presentation on right side, while $50 \%$ patients had clinical presentation on left side; 10 cases $(16.67 \%)$ had bilateral clinical presentation. Similar to our study, Shivakumar et al also found that left side was more commonly involved than the right side. Bilateral T.M 
perforation was seen in $24 \% .{ }^{10}$ However, no explanation has been given for more involvement of left ear than right ear.

Saha et al in their study found bilateral ear disease in 30\% cases. Right ear disease was in $20 \%$ and left ear disease was in $50 \%$ of the cases. 11

In this study, we found that $30 \%$ of the total cases had preoperative ear discharge for $7-12$ months followed by $21.67 \%$ having otorrhoea for $13-24$ months followed by 7 patients $(11.67 \%)$ for each duration of 25 - 36 months, 49 60 months and > 61 months respectively; $8.33 \%$ and $5 \%$ cases of the cases had history of ear discharge for less than 6 months and 37 - 48 months respectively.

Kolo et al observed that the range of duration of ear discharge varied from 14 months to 20 years with mean duration 8.515 years (SD 8.599).12

In our study, we found that $40 \%$ of the cases had large central T.M perforation followed by $31.67 \%$ of patients having subtotal perforation and $28.33 \%$ of cases having medium sized T.M perforation.

However, Kumar et al in their study observed that $43.75 \%$ had moderate TM perforation, $14.06 \%$ had large TM perforation and $32.81 \%$ had subtotal TM perforation. ${ }^{13}$

Kamath et al found $40.83 \%$ of cases having large TM perforation, $35.83 \%$ of cases with medium TM perforation and subtotal perforation was seen in $16.67 \%$ of the cases. ${ }^{14}$

Shivakumar et al observed that $57 \%$ of the cases had medium-sized perforation, while small perforation was seen in $43 \%$ of the cases. ${ }^{15}$

Our study found sclerotic mastoid in $66.67 \%$ cases followed by pneumatisation of mastoid in $21.67 \%$ (13) cases and diploic mastoid in 7 cases (11.67\%).

Sunita et al observed that on x-ray of mastoids, pneumatisation was seen in $30 \%$, diploeic in $8 \%$, sclerosed mastoid in $54 \%$ and cavity in $8 \%$ of the cases. On HRCT temporal bone, pneumatisation was seen in $38 \%$, diploeic in $4 \%$, sclerosed in $50 \%$ and cavity in $8 \%$ of the cases. ${ }^{16}$

Air-bone gap, ABG was in the range of $31-40 \mathrm{db}$ in 17 cases in Group A and 18 cases in Group B respectively; 13 cases in Group A had ABG in the range of 21 - $30 \mathrm{db}$. In Group $B 11$ cases had $A B G$ in the range of $21-30 \mathrm{db}$, while 1 case had $A B G$ in the range of $41-50 \mathrm{db}$.

The mean preoperative air-bone gap, ABG in Group A and Group B were $31.766 \pm 3.94 \mathrm{db}$ and $32.03 \pm 4.23 \mathrm{db}$ respectively. The p value was 0.8063 (calculated by Student's ' $\mathrm{T}$ ' test), which was statistically insignificant.

Kamath et al observed that preoperative mean ABG in the group undergoing myringoplasty alone was $34.69 \pm 11.6$, while it was $36.019 \pm 11.87$ in patients undergoing cortical mastoidectomy with tympanoplasty. ${ }^{14}$ Our study is in correlation with this particular study.

Kaur et al in their study observed that the mean preoperative air conduction in group chosen for tympanoplasty was $35.44 \pm 6.862 \mathrm{db}$, while in the group undergoing tympanoplasty with cortical mastoidectomy it was $36.96 \pm 7.348 \mathrm{db}$. The $p$ value was 0.465 .17 The findings are also similar to our study.

The mean postoperative ABG calculated at $3^{\text {rd }}$ followup in Group A and Group B were $21.866 \pm 4.98 \mathrm{db}$ and $21.366 \pm$ $4.16 \mathrm{db}$ respectively. The $\mathrm{p}$ value was 0.6746 , which was statistically insignificant.

We concluded in the study that gain in hearing at the end of $12^{\text {th }}$ week of surgery in Group A was $9.90 \pm 1.81 \mathrm{db}$, while hearing gain in the Group B was $10.666 \pm 2.07 \mathrm{db}$. The p value calculated by Student's ' $T$ ' test was 0.1305 , which was statistically insignificant.

From the above observation, we can conclude that surgical outcome of myringoplasty and type 1 tympanomastoidectomy in terms of hearing improvement is similar.

Kamath et al observed that postoperative ABG at $3^{\text {rd }}$ month was $23.82 \pm 1039 \mathrm{db}$ and $24.09 \pm 11.02 \mathrm{db}$ in the group undergoing myringoplasty alone and tympanoplasty along with cortical mastoidectomy respectively. ${ }^{14}$ The hearing improvement was $11.45 \pm 5.53 \mathrm{db}$ and $11.83 \pm 5.93$ $\mathrm{db}$ in patients undergoing myringoplasty and tympanoplasty along with cortical mastoidectomy respectively, which was statistically insignificant $(\mathrm{p}=<0.001) .{ }^{14}$ This finding is in correlation to our study.

Kaur et al observed that gain in hearing was $7.64 \pm 5.787$ and $8.84 \pm 5.129$ respectively in groups undergoing tympanoplasty alone and tympanoplasty along with cortical mastoidectomy, which was statistically insignificant $(\mathrm{p}=$ $0.442) .{ }^{17}$

Mishiro et al found that the rates of the postoperative airbone gap within $20 \mathrm{~dB}$ were $81.6 \%$ in group of tympanoplasty with mastoidectomy and $90.4 \%$ in group tympanoplasty alone without a statistically significant difference. They concluded that mastoidectomy is not helpful in tympanoplasty for non-cholesteatomatous COM, even if the ear is discharging. ${ }^{18}$

Bhat et al observed that there were no statistically significant differences in hearing improvement in tympanoplasty with or without cortical mastoidectomy. ${ }^{19}$

Ramakrishnan et al found that the ABG was $12.55 \pm 12.98$ $\mathrm{db}$ and $12.71 \pm 11.54 \mathrm{db}$ in the group undergoing tympanoplasty with and without mastoidectomy respectively $(\mathrm{P}=\mathrm{NS}) .20$

Balyan et al observed that postoperative ABG was $19.4 \mathrm{db}$ and $20.1 \mathrm{db}$ in tympanoplasty with and without cortical mastoidectomy respectively and hence no statistically significant difference. ${ }^{21}$

Successful graft uptake postoperatively at $3^{\text {rd }}$ followup (12th week) was seen in $83.33 \%$ of cases in Group A and in $80 \%$ cases in Group B respectively. However, the p value was 1.00 , which was statistically insignificant.

Dry ear was achieved in 26 cases (86.67\%) in Group A and 28 cases (93.37\%) in Group B respectively at the end of $12^{\text {th }}$ week. The $\mathrm{p}$ value was 0.6707 (calculated by Fisher's exact test), which was statistically insignificant.

Kamath et al observed that graft success rates were $80 \%$ in myringoplasty and $88.33 \%$ in group of cortical mastoidectomy with myringoplasty and there was no statistically significant difference. ${ }^{14}$

In the study by Mishiro et al, graft success rates were $90.5 \%$ in group of tympanoplasty with cortical mastoidectomy and $93.3 \%$ in group of tympanoplasty alone and there was no statistically significant difference. ${ }^{18}$

Tawab et al in their prospective study observed that there was no significant difference in graft uptake between the myringoplasty alone group $(70 \%)$ and cortical mastoidectomy group $(80 \%)(\mathrm{P}=0.7) .^{22}$

Balyan et al in the study observed that successful graft taken up was seen in $89.2 \%$ and $85.7 \%$ cases in myringoplasty alone and tympanoplasty with cortical 
mastoidectomy respectively, which was statistically insignificant. ${ }^{21}$

Tawab et al also observed that there was no significant difference in ear dryness between the myringoplasty alone group (75\%) and cortical mastoidectomy group (90\%) (P = $0.4) .22$ Thus, from our study and review of the above studies we can conclude that gain in hearing; rate of successful graft uptake and dryness of ear achieved in both the groups of myringoplasty and type 1 tympanomastoidectomy are similar.

\section{CONCLUSION}

Chronic otitis media still constitutes a major public health problem in general population of the districts of upper Assam. Goal of surgical management of tubotympanic type of COM is to close the tympanic membrane perforation and clinical improvement in the form of gain in hearing postoperatively and discharge free ear. Myringoplasty and tympanomastoidectomy has been identified as an effective method of treatment of chronic ear infection resistant to antibiotic therapy, but the effect of mastoidectomy on patients without evidence of active infectious disease remains highly debated and unproven.

Our study concluded that surgical outcomes of myringoplasty and type 1 tympanomastoidectomy in tubotympanic type of chronic otitis media in terms of gain in hearing, graft uptake and dryness of ear were statistically similar.

Therefore, while considering the addition of a mastoidectomy to a myringoplasty, the performing surgeon should consider the potential risks and costs to the patient.

However, unbiased selection of cases and study in a larger population and for longer duration of followup needs to be done to re-affirm our conclusion and to analyse whether tympanomastoidectomy prevents future recurrence and disease progression.

\section{REFERENCES}

[1] WHO. Chronic suppurative otitis media burden of illness and management options. Geneva: World Health Organization 2004.

[2] Orji F. A survey of the burden of management of chronic suppurative otitis media in a developing country. Ann Med Health Sci Res 2013;3(4):598-601.

[3] Ibekwe TS, Nwaorgu OG. Classification and management challenges of otitis media in a resourcepoor country. Niger J Clin Pract 2011;14(3):262-9.

[4] Telian SA. Chronic Otitis Media. Snow JB, ed. Ballenger's otorhinolaryngology head and neck surgery. $16^{\text {th }}$ edn. Hamilton, Ontario: BC Decker 2003:261-93.

[5] Gopen Q. Pathology and clinical course of the inflammatory diseases of the middle ear. In: Gulya AJ, ed. Glasscock-Shambaugh surgery of the ear. $6^{\text {th }}$ edn. Shelton, CT: People's Medical Publishing House 2010:425-36.

[6] Haynes D. Canal wall up mastoidectomy. In: Gulya A, ed. Glasscock-shambaugh surgery of the ear. $6^{\text {th }}$ edn. Shelton, CT: People's Medical Publishing House 2010:501-14.

[7] Indorewalla S, Adedeji TO, Indorewala A. Tympanoplasty outcomes: a review of 789 cases. Iran J Otorhinolaryngol 2015;27(79):101-8.
[8] Browning GG, Gatehouse S, Calder IT. Medical management of active chronic otitis media: a controlled study. J Laryngol Otol 1988;102(6):491-5.

[9] Yaor MA, El-Kholy A, Jafari B. Surgical management of chronic suppurative otitis media: a 3 year experience. Annals of African medicine 2006;5(1):24-7.

[10] Shivkumar KL, Joshym S. Role of cortical mastoidectomy in inactive, mucosal type of chronic otitis media. JEBMH 2014;1(7):509-17.

[11] Saha AK, Munsi DM, Ghosh SN. Evaluation of improvement of hearing in type I tympanoplasty \& its influencing factors. Indian J Otolaryngol Head Neck Surg 2006;58(3):253-7.

[12] Kolo ES, Ramalingam R. Hearing results post tympanoplasty: our experience with adults at the KKR ENT Hospital, India. Indian J Otolaryngol Head Neck Surg 2012;66(4):365-8.

[13] Kumar N, Chilke D, Puttewar M. Clinical profile of tubotympanic CSOM and its management with special reference to site and size of tympanic membrane perforation, eustachian tube function and three flap tympanoplasty. Indian J Otolaryngol Head Neck Surg 2011;64(1):5-12.

[14] Kamath MP, Sreedharan S, Rao AR, et al. Success of myringoplasty: our experience. Indian J Otolaryngol Head Neck Surg 2013;65(4):358-62.

[15] Shivkumar KL, Joshym S. Role of cortical mastoidectomy in inactive, mucosal type of chronic otitis media. JEBMH 2014;1(7):509-17.

[16] Sunita M. Sambandan AP. Importance of pre-operative HRCT temporal bone in chronic suppurative otitis media. Odisha J of Otorhinolaryngology \& Head and Neck Surgery 2015;9(1):10-2.

[17] Kaur M, Singh B, Verma BS, et al. Comparative evaluation between tympanoplasty alone \& tympanoplasty combined with cortical mastoidectomy in non-cholesteatomatous chronic suppurative otitis media in patients with sclerotic bone. IOSR Journal of Dental and Medical Sciences (IOSR-JDMS) 2014;13(6):40-5.

[18] Mishiro Y, Sakagami M, Takahashi Y, et al. Tympanoplasty with and without mastoidectomy for non-cholesteatomatous chronic otitis media. Eur Arch Otorhinolaryngol 2001;258(1):13-5.

[19] Bhat KV, Naseeruddin K, Nagalotimath US, et al. Cortical mastoidectomy in quiescent, tubotympanic, chronic otitis media: is it routinely necessary? J Laryngol Otol 2008;123(4):383-90.

[20] Ramakrishnan A, Panda NK, Mohindra S, et al. Cortical mastoidectomy in surgery of tubotympanic disease. Are we overdoing it? Surgeon 2011;9(1):22-6.

[21] Balyan FR, Celikkanat S, Aslan A. Mastoidectomy in noncholesteatomatous chronic suppurative otitis media: is it necessary? Otolaryngol Head Neck Surg 1997;117(6):592-5.

[22] Tawab HMA, Gharib FM, ElSharkawy LS, et al. Myringoplasty with and without cortical mastoidectomy in treatment of noncholesteatomatous chronic otitis media: a comparative study. Clin Med Insights Ear Nose Throat 2014;7:1923. 